\title{
Ideias e método de Celso Furtado para pensar o século $X X I^{\star}$
}

\section{Celso Furtado's ideas and method for thinking the 21st century}

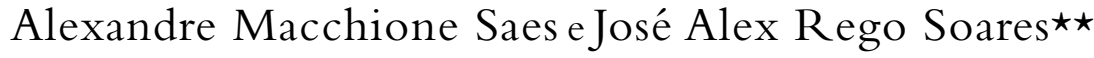

Resumo: $\mathrm{O}$ artigo discute como o método e a interpretação de Celso Furtado formaram sólidas bases para a contínua análise das economias brasileira e internacional ao longo de quase cinco décadas de trabalho intelectual. O método histórico estrutural permitiu que Celso Furtado pudesse observar as transformações políticas e econômicas mundiais, revisando suas próprias teses e indicando caminhos para que a sociedade possa enfrentar os desafios de sua geração. $O$ artigo confronta as ideias de Furtado com a política econômica dos governos do PT, demonstrando o vigor da intepretação e do método de análise do autor como instrumento poderoso no sentido de construir projetos de transformação social.

Palavras-chave: Celso Furtado. Método histórico-estrutural. Governos do PT.

Abstract: The paper discusses how Celso Furtado's method and interpretation formed solid bases for a continuous analysis of the Brazilian and international economies over almost five decades of intellectual work. The structural historical method allowed Celso Furtado to observe the political and economic changes in the world, reviewing his own theses and indicating ways for society to face the challenges of its generation. The paper confronts Furtado's ideas with the economic policy of PT governments, demonstrating the strength of the author's interpretation and analysis method as a powerful instrument in the sense of building social transformation projects.

Keywords: Celso Furtado. Historical-structural method. PT's government.

\footnotetext{
* Submissão: 09/01/2021 | Aprovação: 15/01/2021 | DOI: 10.29182/hehe.v24i1.789

Os autores agradecem a Flávio Saes e Renata Bianconi por suas sugestões, assim como aos participantes das disciplinas “Celso Furtado, intérprete do Brasil”, ministradas na graduação da FEA e na pós-graduação do Instituto de Estudos Brasileiros (com Alexandre de Freitas Barbosa), cujos debates inspiraram parte dos argumentos do texto.

$\star \star$ Respectivamente: (1) Professor do Departamento de Economia da FEA/USP, Bolsista Produtividade CNPq | E-mail: alexandre.saes@usp.br | ORCID:0000-0003-4274-1993 | (2) Pós-doutorado em Economia (FEA/USP) | E-mail: jalex.economia43@gmail.com | ORCID:0000-0001-9188-5040
} 


\section{Introdução}

A celebração do centenário de Celso Furtado em 2020 mostrou o vigor de sua obra e de suas ideias entre os mais fieis "furtadianos", como também entre estudantes, membros de movimentos sociais e intelectuais dos mais diversos campos do conhecimento e de variados espectros políticos. Foram dezenas de eventos, homenagens e publicações para celebrar o mais importante economista brasileiro, passados dezesseis anos de seu falecimento.

Em trabalhos anteriores já apontamos como as obras de Celso Furtado, especialmente Formação econômica do Brasil, permanecem presentes nos cursos de graduação de Economia; como a vida e obra de Celso Furtado passaram a ser objeto de estudos na pós-graduação do país; assim como suas ideias movimentaram o debate econômico e político nas últimas duas décadas. ${ }^{1} \mathrm{~A}$ ampliação dos estudos sobre as interpretações de Celso Furtado, somada às iniciativas como a criação do Centro Internacional Celso Furtado e do periódico Cadernos do Desenvolvimento, tanto quanto as publicações dos Arquivos Celso Furtado e de suas obras definitivas, tem descortinado novos olhares para uma extensa obra de um economista que buscou, por meio da interdisciplinaridade, produzir uma interpretação e um projeto de Brasil.

Celso Furtado foi um intelectual formado pelo ambiente político e social do pós-guerra. Seu projeto de transformação social foi sedimentado em torno da reconstrução da Europa, observando o papel dos diferentes modelos de estados de bem-estar e dos instrumentos de crescimento econômico e coesão social das economias centrais, como também do novo papel de órgãos internacionais criados no pós-guerra. Afinal, para os europeus era uma fase de tomada de consciência da necessária reconstrução de sua sociedade, no intuito de garantir meios para superar a miséria e a destruição das décadas anteriores. Fortalecendo os instrumentos de planejamento e intervenção do Estado, os governos promoveriam políticas com valorização de suas instituições democráticas, produzindo uma significativa mediação das relações entre capital e trabalho, conduzindo a sociedade na chamada Era de Ouro do capitalismo. ${ }^{2}$

Tendo experienciado essa fase inicial de reconstrução europeia após a Segunda Guerra Mundial, Celso Furtado viu na oportunidade de cursar o

\footnotetext{
${ }^{1}$ Para a presença de Formação econômica do Brasil nos cursos de graduação, ver: Saes, Manzatto e Sousa (2015). Para a assimilação da obra de Celso Furtado nos últimos sessenta anos, ver: Saes e Manzatto (2021).

${ }^{2}$ Para a Era de Ouro do capitalismo, conferir A era dos Extremos, de Eric Hobsbawm (1994, Parte 2), e História econômica geral, de Saes e Saes (2013, cap.13).
} 
doutorado em Paris uma ocasião para participar de um verdadeiro "laboratório social" (Furtado, 2014, p. 28). A bagagem acumulada nos anos imediatos ao final do conflito, assim como sua trajetória seguinte, de economista da Cepal e, ainda mais tarde, de professor universitário exilado em Paris, reforçaram sua aposta na formação de uma sociedade que pudesse oferecer alguma homogeneização social, desfrutando de autonomia - a partir de seus centros de decisão -, para produzir políticas voltadas para o bem-estar de seus cidadãos, em que a industrialização e o planejamento estatal seriam os meios para alcançar tais objetivos.

As agruras da guerra, as profundas cicatrizes produzidas pelos regimes totalitários e a devastação e pobreza herdadas dos anos anteriores exigiram dos intelectuais europeus o confronto de seus espaços de experiência com seus horizontes de expectativa. Italo Calvino, por exemplo, mediante a trilogia Nossos antepassados, retorna ao cenário da Idade Média para construir alegorias que refletiam os impasses de sua Itália contemporânea. O realismo fantástico das personagens do barão nas árvores, do visconde partido ao meio e do cavaleiro inexistente, responde por meio de alegorias às disputas dicotômicas existentes no mundo da Guerra Fria. ${ }^{3}$

Celso Furtado, partindo da realidade das economias subdesenvolvidas, assim como Calvino, buscou encontrar respostas criativas para os desafios de seu tempo. Esse percurso exigiu seu afastamento de projetos monolíticos, tanto difundidos pela ideologia do progresso, presente na teoria do desenvolvimento de inspiração neoclássica, como pela crítica ao modelo marxista autoritário. A vida de Furtado ilustra o percurso de um intelectual independente, como se vestisse as fantasiosas personagens de Calvino, para enfrentar os debates econômicos de seu tempo, encontrando projetos de futuro alternativos.

$\mathrm{O}$ artigo, portanto, discute as ideias e o método de Celso Furtado, avaliando como suas proposições podem nos ajudar a pensar o Brasil do século XXI. Não nos restam dúvidas de que a conjuntura internacional, os dilemas econômicos e os impasses sociais se transformaram nos últimos cinquenta anos, desde quando as pioneiras contribuições de Celso Furtado começaram a disputar o debate político e intelectual. Não obstante, seria um erro acreditar que as ideias de Celso Furtado, ao longo de sua trajetória intelectual, também

\footnotetext{
${ }^{3}$ A trilogia Nossos antepassados, de Italo Calvino, é formada pelos livros O visconde partido ao meio (1952), O Barão nas árvores (1957) e O cavaleiro inexistente (1959). Sobre o realismo fantástico de Calvino, ver Sousa (2007).
} 
não acompanharam as mudanças ou tampouco responderam às novas demandas da sociedade contemporânea.

O contínuo esforço de revisão de suas próprias teses e formulações, como ocorrido entre os anos de 1970 com obras como O mito do desenvolvimento econômico (1974) e Criatividade e dependência na civilização industrial (1978), como também a atenção para as novas agendas de pesquisa e de intervenção política, tal como a questão ambiental desde o grupo de Roma até a Rio 1992, ilustram a atualização do pensamento de Furtado a cada novo contexto. Assim, por meio do confronto das ideias e do método de Celso Furtado com as políticas econômicas dos governos do PT, buscamos evidenciar o vigor da interpretação do economista para pensar o século XXI.

\section{Celso Furtado, o barão nas árvores da ciência econômica}

Filho primogênito do Barão Rondó, o jovem Barão Cosme Chuvasco - personagem de Calvino - se revolta contra as exigências disciplinadoras do pai, em meio às notícias sobre a Revolução Francesa e a disseminação das ideias iluministas, e se refugia nas copas das árvores do palácio. Celso Furtado, como o Barão, ao longo dos anos 1950 rompeu com seus pares, proferiu "heresias" e foi "heterodoxo" para ampliar seus olhares sobre o funcionamento da economia (Furtado, 1998, p. 10; 2002, p. 80). ${ }^{4}$ Refutando o hermetismo da teoria neoclássica e subindo pelos galhos do estruturalismo latino-americano, o economista brasileiro pode encontrar um olhar mais amplo, arejado e complexo para compreender os sentidos da periferia na dinâmica da economia mundial. Furtado, tanto quanto o Barão, permaneceria sobre as árvores para o resto de sua vida, debatendo com economistas, mas por meio de um arcabouço significativamente crítico às teses canônicas da ciência econômica e profundamente interdisciplinar no método.

Em suma, se o estruturalismo latino-americano produziu a mais potente leitura sobre a realidade econômica da região, seu vigor deve ser atribuído em grande medida como resultado da proposição de um "enfoque analítico próprio" (Bielschowsky, 2000, p. 16). Ao questionar os modelos de comércio internacional, as teorias convencionais de crescimento econômico

\footnotetext{
${ }^{4}$ Tema recorrente na produção de Celso Furtado, desde $A$ pré-revolução brasileira (1962, caps. 6 e 7), ser heterodoxo para o autor era romper com o pensamento convencional, buscando "uma base metodológica sólida”, em que "a imaginação é um instrumento poderoso de trabalho" (Furtado, 1962, p. 98).
} 
e a noção de estágios de desenvolvimento, o enfoque histórico estruturalista indicava o caráter particular do padrão de inserção internacional dos países periféricos na economia capitalista, apontando, a partir de então, para as tendências e para as contradições estruturais internas desses países.

Foi por meio do método histórico e da investigação das especificidades da realidade latino-americana, dentro do amplo quadro da economia internacional, que as proposições cepalinas encontrariam espaço na história do pensamento econômico.As formulações pioneiras do "manifesto latino-americano" de Raúl Prebisch, tanto quanto os desdobramentos posteriores apresentados por economistas como Celso Furtado - que desempenharia papel decisivo tanto nas formulações teóricas, como nas análises históricas -, pautariam a ampla agenda sobre o desenvolvimento periférico dos anos 1950: a discussão sobre a deterioração dos termos de intercâmbio, sobre a inflação e o desemprego estrutural, sobre a inelasticidade da oferta agrícola e o caráter dual das economias subdesenvolvidas (Fonseca, 2021, p. 227). ${ }^{5}$

Pedro Fonseca, partindo da análise do anexo metodológico de Teoria de política do desenvolvimento econômico, argumenta que a tensão existente entre os modelos hipotético-dedutivos típicos da teoria econômica e a "dinamização dos parâmetros" desses modelos, como forma de captar as especificidades históricas e regionais, exigiu que Celso Furtado produzisse uma ruptura com a matriz estrutural da teoria econômica neoclássica, para inserir a noção de tempo em sua análise. Recusando-se a simplificar a explicação da realidade ao promover o transplante da análise sincrônica para o eixo diacrônico, seu método percorria um exame dialético, deixando de tratar os fenômenos como variáveis fixas no tempo e espaço. Essa "dinamização dos parâmetros", como afirma Fonseca, "exige a incorporação de dimensões políticas, culturais, institucionais, legais, religiosas, dentre outras" (Fonseca, 2021, p. 230-233).

Por isso, para Furtado, o estruturalismo "econômico" latino-americano não deve ser comparado com o estruturalismo francês, “cuja orientação geral tem sido privilegiar o eixo das sincronias na análise social e estabelecer uma sintaxe das disparidades nas organizações sociais". A escola latino-americana, para Furtado, evidencia a centralidade dos parâmetros não econômicos para compreender o comportamento das variáveis econômicas, sendo ainda mais

\footnotetext{
${ }^{5}$ Essa geração de economistas cepalinos produziria, entre as décadas de 1950 e 1960, relevantes obras que ofereceriam a legitimação histórica ao estruturalismo latino americano, tais como: Chile: um caso de desarollo frustrado (1959) de Aníbal Pinto; La economía argentina: las etapas de su desarrollo y problemas actuales (1963), de Aldo Ferrer; e, Formação econômica do Brasil, de Celso Furtado, possivelmente a obra mais relevante do período (Bielschowsky, 2000, p. 22-23; Love, 1981, p. 239).
} 
pertinente essa observação com horizontes temporais alargados e em "sistemas econômicos heterogêneos, social e tecnologicamente, como é o caso das economias subdesenvolvidas" (Furtado, [1967] 1977, p. 83).

O método de Furtado é, portanto, acima de tudo histórico. Como defende Bresser-Pereira (2001, p. 19), apesar de uma poderosa capacidade de inferência e dedução, sua análise parte da observação da realidade. Ainda que o método desperte alguma semelhança com aquele de outras escolas de pensamento econômico de caráter histórico-indutivo, tais como da escola histórica alemã ou do institucionalismo americano, Bresser-Pereira defende que Furtado e o estruturalismo não pregam a recusa da teoria econômica, mas sim sua mediação com as especificidades históricas.

A perspectiva teórica se alicerça, em suma, tanto num caráter abstrato como também histórico, combinando criatividade interpretativa com rigor lógico. Por isso reconhece a centralidade das instituições no processo histórico, não como instituições que podem ser apartadas da realidade, como parte da literatura econômica mais recentemente se propôs a interpretar. As instituições estão incrustadas na base do Estado, do desenvolvimento político e social de cada nação (Bresser-Pereira, 2001, p. 30-32).

Ainda que fosse possível admitir a existência de algumas proposições teóricas, não parece ser possível definir a Cepal propriamente como uma "escola de pensamento econômico da América Latina". ${ }^{6} \mathrm{O}$ estruturalismo latino-americano se aproxima mais de arcabouço analítico - e não propriamente teórico -, oferecendo um método histórico-indutivo em diálogo com abstrações teóricas que permitem captar as regularidades da dinâmica econômica e social. Em suma, como argumenta Bielschowsky, não há rigidez nos esquemas de análise, mas acomodação da evolução, sem perda de coerência na utilização do método (Bielschowsky, 2000, p. 21).

É desse movimento analítico que Furtado estrutura sua visão de mundo. Ainda que com formulações teóricas, sistematizadas em Desenvolvimento e subdesenvolvimento (1961) e, mais tarde, buriladas em Teoria e politica do desenvolvimento econômico (1967), seu diálogo com cada conjuntura é permanente. A transformação do capitalismo internacional entre as décadas de 1960 e 1970, portanto, exigiu que o autor reavaliasse algumas de suas proposições, reformulando o peso e o sentido das variáveis econômicas, políticas e sociais,

\footnotetext{
${ }^{6}$ Essa é a posição que defende Ricardo Bielschowsky (2000, p. 21-22); Octavio Rodríguez (2009, p. 53), por outro lado, admite um corpo teórico mais homogêneo.
} 
alcançando então, o que Carlos Mallorquin (2005, cap. 7) qualifica como sua "grande teoria".

Nos anos 1950, a original formulação sobre o subdesenvolvimento apresentada pela Cepal e por Celso Furtado, em alguma medida, era uma teoria constituída pelo negativo: a contraposição à teoria das vantagens comparativas, apresentando a ideia da deterioração dos termos de intercâmbio; a negação das teses liberais de um mercado como regulador social, defendendo o planejamento e a intervenção do Estado, com aproximação das teses keynesianas de políticas anticíclicas; a oposição às teses monetaristas, oferecendo a análise da inflação estrutural; e, finalmente, à contestação da noção de estágios de desenvolvimento, o estruturalismo apresenta a economia mundial como um sistema - capitalista - de relações econômicas e de poder desiguais entre nações.

Por outro lado, com o golpe de 1964 e o exílio, Celso Furtado inicia uma nova fase de reflexão, significativamente mais crítica, tanto sobre a capacidade da industrialização garantir a superação do subdesenvolvimento como sobre o rumo político e o projeto de país colocados em prática com o regime militar. Num curto espaço de tempo, o economista pisaria em diferentes e renovados espaços de diálogo: tendo deixado a posição de economista da Cepal para assumir cargos na administração do governo brasileiro até seu exílio, no exterior passaria alguns meses entre os seminários do Ilpes em Santiago; um ano como pesquisador em Yale, mantendo contato com Stephen Hymer e seus estudos sobre as multinacionais; e, finalmente, como professor de Teoria do desenvolvimento na Sorbonne, em Paris. ${ }^{7}$

No período, o "cavaleiro andante" buscava compreender as razões que teriam levado o Brasil à crise do modelo de substituição de importações e ao fracasso do projeto nacional-desenvolvimentista. Internacionalmente, seus olhares para a nova conformação da economia internacional indicavam o poder das transnacionais em oposição aos centros internos de decisão. Gradativamente, Celso Furtado se coloca novas questões, revisa pressupostos presentes em suas formulações pretéritas e, enfim, apresenta uma nova e original análise sobre a dinâmica das economias subdesenvolvidas.

Em parte, essas respostas foram lançadas com Subdesenvolvimento e estagnação na América Latina, de 1966. Furtado inicia com a obra sua avaliação sobre o caráter da industrialização subdesenvolvida, incompatível com a necessidade

\footnotetext{
${ }^{7}$ Para acompanhar as ideias e trajetória de Celso Furtado no exílio, ver Bianconi (2014).
} 
de absorção da mão de obra subempregada. A perspectiva receberia posteriormente tratamento mais aprofundado, a partir dos debates gerados pela própria obra e pela assimilação de temáticas em discussão no período, mas a original abordagem já analisava de maneira integrada as estruturas produtivas e distributivas (Bielschowsky, 2020). ${ }^{8}$

Entre o final da década de 1960 e o início de 1970, podemos destacar as contribuições de Fernando Henrique Cardoso e Enzo Faletto, de Maria da Conceição Tavares e José Serra, e de Francisco de Oliveira, como as obras que estabeleceram algum tipo de diálogo com as proposições de Celso Furtado.

A obra Dependência e desenvolvimento na América Latina, de Fernando Henrique Cardoso e Enzo Faletto, seria a abertura para uma maior valorização dos aspectos políticos e sociais, dando destaque para os determinantes internos e para a dinâmica social no processo de transformação da sociedade. Os autores partiam da crítica à "perspectiva otimista" existente no projeto de desenvolvimento nacional dos anos 1950, explicitando as razões para industrialização por substituição de importações não ter alcançado seu objetivo. A proposição metodológica nova, nesse sentido, era a de incorporar à interpretação econômica do desenvolvimento, uma análise sociológica (Cardoso; Faletto, [1967] 1970, p. 13-15).

Tal percurso interpretativo estava de acordo com as evidências trazidas por Cardoso anos antes, em seu trabalho sobre o empresariado industrial, que apontava para a inexistência de uma burguesia nacional no país. ${ }^{9}$ Para o autor, a recente e heterogênea burguesia não cumpriria com seu papel histórico, isto é, com o papel de assumir a liderança de uma revolução brasileira, conforme crença esposada tanto pelas interpretações marxistas quanto pelas perspectivas nacional-desenvolvimentistas. $\mathrm{O}$ caráter associado de parte do empresariado nacional, conforme ficaria explícito no período militar, bloqueava a efetivação do projeto nacional-desenvolvimentista ou de uma "revolução" brasileira.

\footnotetext{
${ }^{8}$ Para a análise de Subdesenvolvimento e estagnação na América Latina, ver Bianconi (2016) e Coutinho (2019).

${ }^{9}$ Estamos falando do livro Empresário industrial e desenvolvimento econômico no Brasil, resultado da tese de livre-docência apresentada em 1963. Como alertava o autor pouco antes do golpe militar, os industriais brasileiros compunham uma "camada social recente e heterogênea", sem representar claros interesses de classe, "uma consciência" ou "uma ideologia industrial” (Cardoso, 1972, p. 177). Como reitera no prefácio de 1972, Cardoso considera que o mérito de sua obra era captar a análise estrutural que se materializaria com o golpe militar, mostrando a fragilidade de uma ideologia nacional que abarcasse a aliança de uma burguesia nacional, das massas urbanas e do Estado (Cardoso, 1972, p. 14).
} 
Em Dependência e desenvolvimento, na parte "Análise integrada do desenvolvimento", Cardoso e Faletto colocam em evidência a "atuação das forças sociais", que teriam papel de manter ou modificar o caráter da estrutura social, portanto, trazendo para a discussão econômica de desenvolvimento as disputas sociais. A análise da dependência para os autores garantia a superação de uma análise "mecânica-causal", que enfatiza a determinação externa.Assim, se a situação de subdesenvolvimento era produto da expansão do capitalismo, enfatizando as formas das relações econômicas subdesenvolvidas no mercado mundial, a dependência era a manifestação social das articulações dos grupos internos com os externos (Cardoso; Faletto, [1967] 1970, p. 25-26).

O artigo "Além da estagnação", de Maria da Conceição Tavares e José Serra, por seu turno, era uma crítica direta ao livro de Furtado de 1966, questionando a ideia de que existiria incompatibilidade entre crescimento (desenvolvimento capitalista para os autores) e concentração de renda. O esgotamento da industrialização por substituição de importações não era uma crise de caráter estrutural, mas "uma transição a um novo esquema de desenvolvimento capitalista". Por isso, a marginalização e o subemprego, reforçados pela exclusão social, não deveriam ser observados como "problemas fundamentais para a dinâmica econômica capitalista", pois,"enquanto o capitalismo brasileiro desenvolve-se de maneira satisfatória, a nação, a maioria da população, permanece em condições de grande privação econômica" (Tavares; Serra [1971] 2000, p. 592-593). ${ }^{10}$

A crítica de Tavares e Serra às teses sobre estagnação acaba revisitando o sentido de dependência e desenvolvimento de Fernando Henrique Cardoso e Enzo Faletto. Os autores, ao percorrerem os ciclos da economia brasileira, encontram o aprofundamento da crise dos anos 1960 tanto pela queda do investimento público, quanto também pelo "ataque direto ao capital estrangeiro". Isto é, a retomada do crescimento da economia brasileira, naquela altura, poderia passar a um "esquema de expansão" por meio de estímulos do próprio sistema, "sem que isso significasse o enfraquecimento dos laços de dependência externa" (Tavares; Serra [1971] 2000, p. 605).

\footnotetext{
${ }^{10}$ Dois anos mais tarde, em Um projeto para o Brasil, Furtado reitera o diagnóstico da estagnação e sugere que produzir uma maior distribuição de renda, garantindo o consumo das classes baixas seria um meio decisivo para superar a crise estrutural. Chico de Oliveira faz sua crítica ao diagnóstico de Furtado dizendo que a obra "é a utopia do consumismo popular, pois não apresenta uma explicação adequada de como, sem transferência do poder ou mudanças fundamentais na sua estrutura, sem mudanças na estrutura de classes [...], sem mudanças na estrutura de apropriação e propriedade do excedente econômico [...]" (Oliveira, 2003b, p. 31).
} 
Crítica à razão dualista, obra de Chico de Oliveira publicada em 1972, colocaria em questão a oposição de moderno e arcaico, mostrando como a dinâmica da economia brasileira dependia justamente do setor atrasado para viabilizar o capitalismo periférico. O moderno, diz o autor, "cresce e se alimenta da existência do atrasado"; na periferia, moderno e arcaico são uma unidade de contrários, que mantêm uma simbiose e organicidade (Oliveira, 1972, p. 30-32).

Em termos práticos, era o setor atrasado da economia, caracterizado por uma ampla mão de obra subempregada - de um exército industrial de reserva -, que garantia ao capitalismo brasileiro manter sua dinâmica, por meio do rebaixamento dos salários e da elevação da taxa de lucros. Em suma, seguindo a crítica de Tavares e Serra, a exclusão econômica de parte da população, antes de ser bloqueio, era o instrumento funcional e dinâmico da economia brasileira. ${ }^{11}$

A partir dos debates do período e das novas evidências da economia internacional, Celso Furtado volta-se ao processo histórico para redefinir os parâmetros de sua teoria. A revisão de suas teses fica significativamente marcada pela abordagem conceitual e histórica empreendida nos primeiros anos da década de 1970. Observando o expressivo crescimento da economia brasileira, recusa-se a definir o processo de crescimento da economia, como fazem seus interlocutores, como "desenvolvimento" capitalista no país. Define o processo como modernização - uma mimetização dos padrões de consumo, sem transformações das estruturas concentradoras de renda do país -, inserindo uma dimensão valorativa para o conceito de desenvolvimento. ${ }^{12}$

Com a publicação de Análise do modelo brasileiro (1972) e $A$ hegemonia dos Estados Unidos e o subdesenvolvimento na América Latina (1973), o economista se insere no debate sobre a dependência. Nessas obras, partindo das críticas sobre a estagnação, sua leitura sobre a oferta ilimitada de mão de obra vai tomando contornos cada vez mais críticos, condição central para redefinir o caráter da heterogeneidade estrutural das economias subdesenvolvidas. Com O mito do desenvolvimento econômico (1974) e Criatividade e dependência (1978), por outro lado, convence-se de que mais do que a superação do subdesenvol-

\footnotetext{
${ }^{11}$ A contribuição de Aníbal Pinto (1970) sobre a heterogeneidade estrutural também deve ser lembrada como pioneira no sentido de problematizar o perfil da industrialização latino-americana.

${ }^{12}$ Sobre o caráter da interpretação de Celso Furtado a respeito da dependência, ver Manzatto e Saes (2021); para uma análise de suas ideias a partir da descoberta do "mito”, ver Mallorquin (2005, cap. 7).
} 
vimento, o desafio colocado para a sociedade é o da própria civilização industrial, o modelo de sociedade capitalista como um todo.

Assim, se antes o fenômeno do subdesenvolvimento estava relacionado especialmente às consequências produzidas pelo padrão desigual de difusão do progresso técnico, Celso Furtado, durante o período de exílio, passa a entender o subdesenvolvimento também como resultado da dimensão social e política. Como indica o autor em $O$ mito do desenvolvimento econômico, o fenômeno da "dependência é mais geral do que o subdesenvolvimento", afinal, "a dependência criou as formações sociais sem as quais é dificil caracterizar um país como subdesenvolvido” (Furtado, 1974, p. 87).

Se explicita, nesse sentido, o diálogo de Furtado com o debate sobre o caráter da dependência dos países periféricos no quadro do capitalismo internacional. Revendo sua tese sobre estagnação, reconhece a possibilidade de uma dinâmica de crescimento econômico com concentração da renda, mesmo com ampliação da exploração, pois "a própria razão de ser desse tipo de industrialização na periferia é a existência de trabalho barato" (Furtado, 1974, p. 92).

Distanciando-se, portanto, da crença na industrialização como mecanismo suficiente para a superação do subdesenvolvimento, de incorporação da massa de trabalhadores subempregados, Furtado incorpora aspectos do debate do período e reavalia a conjuntura econômica internacional para produzir uma nova leitura sobre a conjuntura. A industrialização permanecia como necessária, mas agora não era mais suficiente. E o método histórico era decisivo para que o autor pudesse reter as novas evidências e sugerir caminhos alternativos para a superação dos limites da racionalidade instrumental, impostos pela economia capitalista.

A dimensão da heterogeneidade estrutural, presente nas teses iniciais da Cepal, portanto, assume centralidade na análise de Celso Furtado sobre o caráter da modernização, isto é, da "assimilação indireta da civilização industrial”, por meio dos estilos de vida (Furtado, 1978, p. 65). Esse conceito será elemento basilar em sua leitura sobre a economia mundial de final do século $\mathrm{XX}$, último grande esforço do autor de sintetizar os principais movimentos da economia internacional. 


\section{Celso Furtado, um cavaleiro inexistente no final do século XX?}

Agilulfo Emo, membro da corte de Carlos Magno, em defesa do cristianismo, vive as aventuras medievais como um cavaleiro inexistente: um cavaleiro de excepcionais qualidades, servindo com fé, coragem e dedicação à sua causa, sustentando uma armadura impecável, mas por dentro vazia e solitária. Nesse sentido, Italo Calvino percorre um romance de cavalaria às avessas de Miguel de Cervantes. Enquanto Dom Quixote é um cavaleiro que reproduz atabalhoadamente as memoráveis aventuras dos romances medievais, a atuação de Agilulfo Emo é tão primorosa e infalível, que não podendo ser real, é, portanto, inexistente.

Nos anos 1990, Celso Furtado admite entrar numa batalha quixotesca para enfrentar a hegemonização do discurso econômico liberal. Em sua nota que abre a obra Brasil: a construção interrompida, publicada em 1992, Celso Furtado fala sobre um "sentimento de angústia gerado pelas incertezas que pairam sobre o futuro do Brasil”. Os ares da nova economia, numa ofensiva ideológica alicerçada na defesa do livre-mercado, teriam interrompido a "construção de um sistema econômico nacional", projeto perseguido pela geração do autor, que cimentara a unidade do país e "nos abriu uma grande opção histórica" (Furtado, 1992, p. 9).

Brasil: a construção interrompida pode ser compreendida como o último grande esforço de síntese de Celso Furtado sobre a conjuntura econômica internacional, como também de elaboração de proposições para enfrentar os impasses da sociedade daquele contexto. ${ }^{13}$ Coerente com sua trajetória intelectual, Furtado sumariza os novos tempos, denominados de globalização, reforçando seu olhar crítico para os impasses produzidos pelo capitalismo. Suas apreciações sobre o sistema econômico do período o colocam entre um Dom Quixote e um Agilulfo Emo: entre um cavaleiro que sonha com o passado para remontar o projeto nacional-desenvolvimentista, em crise naquela altura, como também um cavaleiro inexistente, advertindo quase solitariamente os impasses sobre o futuro no contexto de neoliberalismo. $^{14}$

\footnotetext{
13 As três últimas obras publicadas pelo autor, todas compostas por um conjunto de curtos ensaios, Capitalismo Global (1998), O longo amanhecer (1999) e Em busca de um novo modelo (2002), repisam os temas trabalhados em 1992.

${ }^{14}$ Como Bresser-Pereira ilustra: "De volta ao Brasil, depois de uma passagem pelo governo Sarney, em que já não lhe atribuíram funções na área econômica, foi aos poucos se transformando na consciência crítica das novas administrações econômicas que, a partir de 1990, impuseram ao Brasil o credo neoliberal. Foi um
} 
No que diz respeito ao contexto nacional, o Brasil estava imerso no debate sobre uma ampla política de ajustes macroeconômicos, em que a liderança do Fundo Monetário Internacional, por meio dos princípios do Consenso de Washington, recomendava uma série de reformas tendo como finalidade a maior eficiência econômica. Eram as conhecidas medidas de estímulo à elevação da produtividade, por meio da entrada do investimento estrangeiro, da redução das tarifas alfandegárias, da privatização e da desregulamentação das atividades econômicas; era o redimensionamento da atuação do Estado, com maior disciplina fiscal, redução dos gastos públicos e rigorosa política de controle da inflação (Williamson, 1989).

Para Celso Furtado, contudo, o horizonte estava nublado não somente para compreender o futuro do Brasil. Em seu diário, em fevereiro de 1991, vaticina: "O grau de incerteza com respeito ao futuro aumentou" (Furtado, 2019, p. 416). Em suma, o economista brasileiro seguia na contramão de uma tendência otimista observada na literatura econômica internacional daquele momento, em que se defendia tanto a noção de um "fim da história", ou mais tarde, da "nova economia" e da "era da moderação". ${ }^{15} \mathrm{O}$ crescimento econômico da década, a partir de um ciclo americano de investimentos tecnológicos, da difusão de um novo padrão de consumo e da multiplicação dos meios financeiros gerados pela flexibilização do mercado, ofuscava os dilemas geopolíticos e sociais que seriam produzidos pela "globalização", exacerbados nos últimos anos.

As transformações da economia mundial naquela quadra histórica indicavam para Furtado um ambiente de profunda incerteza sobre o cenário internacional: tanto pelo fim da União Soviética, quanto pelos sinais duvidosos sobre a hegemonia política e econômica dos Estados Unidos com o avanço tecnológico e industrial asiático; tanto pela reunificação alemã e pelo complexo avanço do projeto de unificação da Europa; tanto pelo dinamismo da economia internacional conduzido pelas transnacionais, mas também pela perda de governabilidade dos Estados nacionais; tanto pela expansão da capacidade de produção mundial, como pela crescente crise social e ambiental.

período em que Furtado foi quase esquecido. Para muitos era um economista do passado, um nacionalista no tempo da globalização [...]" (Bresser-Pereira, 2006b, p.78).

${ }^{15}$ Para o fim da história, conferir o artigo e livro de Fukuyama $(1989,1992)$. Para a ideia de uma nova era ou para uma fase de grande moderação, conferir: Stiglitz (2003) e Bernanke (2004). Por outro lado, a percepção do historiador marxista, Eric Hobsbawm, em sua Era dos extremos, era também de que o final do século XX oferecia significativas incertezas para o futuro da humanidade. Para uma descrição do período, Saes e Saes (2013), nos capítulos 21 e 24. 
No final de Ares do mundo, terceiro volume de sua obra autobiográfica, publicada em 1991, era possível captar sua preocupação sobre o devir histórico. Discutindo a dimensão de progresso, o autor recoloca sua perspectiva crítica sobre o desenvolvimento ao abordá-la numa dimensão sociológica e cultural. Sintomático pensar como recuperar o "mito do paraíso perdido"isto é, o mito como uma idealização de futuro, num horizonte utópico que teria guiado a humanidade durante o século num sentido do progresso como expressão material -, era, para Furtado, uma forma de colocar em questão a trajetória política e intelectual de sua geração (Furtado, 2014, p. 575-576).

Não podemos deixar de imaginar que a angústia de Furtado em sua autobiografia expressava também o esvaziamento de sua própria utopia de transformação social. O horizonte de expectativa de Furtado almejava a construção de uma sociedade mais igualitária, em que o Estado teria autonomia e capacidade de conduzir um processo real de desenvolvimento. Em certo sentido, o Estado de bem-estar europeu fora esse modelo de sociedade, mas agora nos anos 1990 esse modelo teria sido excluído como possibilidade de futuro por um duplo movimento.

Em primeiro lugar, desde a publicação de $O$ mito do desenvolvimento econômico, estava claro para o economista que as economias subdesenvolvidas não teriam condições de reproduzir a estrutura social e econômica das economias desenvolvidas. O "mito", como o autor concebe a ideologia do desenvolvimento econômico, apenas teria domado os conflitos sociais na proposição de um ideal de futuro, mas cuja participação nos benefícios desse processo era concentrada em poucos grupos. As relações assimétricas eram inerentes ao capitalismo, tanto entre subsistemas econômicos quanto entre formas de exploração social (Furtado, 1974, p. 94).

Por outro lado, nas economias centrais a crise do Estado de bem-estar social, ao longo dos anos 1970, reforçava a ideia de que o padrão de organização social dominante na Era de Ouro do capitalismo dificilmente poderia ser difundido. $\mathrm{O}$ avanço do ideário da economia de mercado, de Estado mínimo e das reformas liberalizantes, fragilizava o papel do Estado como mediador social, responsável pela "dialética do desenvolvimento", como o autor teria explicitado com a fórmula de desenvolvimento das economias centrais (Furtado, 1964, cap. 5).

Em suma, para além de refletir sobre o caminho para a superação do subdesenvolvimento, suas reflexões neste último quarto de século vão colocando em questão o próprio modelo de sociedade em que o capitalismo 
contemporâneo se assentou. Enfim, a partir de Brasil: a construção interrompida, Celso Furtado produz mais do que uma análise sobre a incerteza do futuro do país, mas sugere os limites de uma civilização voltada para a acumulação como fim, e não mais como meio de providenciar os benefícios materiais e imateriais para todos seus membros. Em suma, para Furtado o capitalismo se expressava como um sistema em que a sociedade teria invertido o real sentido entre fins e meios, numa época de acumulação acelerada que produzia uma miragem de progresso como abundância de bens materiais, mas "que pode[ria] conduzir o homem à autodestruição" (Furtado, 2014, p. 580).

No "vasto sertão que ainda está por ser desbravado", em 1992, cinco eram as proposições de Celso Furtado para os jovens economistas. No sentido de enfrentar a distribuição de renda, sua primeira proposta se escora na ideia de "habilitação", de Amartya Sen: uma política para garantir títulos de propriedade para a população rural e urbana, pois o acesso à terra e às moradias era uma privação estrutural que não teria condições de ser solucionada por mecanismos de mercado.

De acordo com as mudanças ocorridas no Brasil naquele momento, a segunda proposição era a de fortalecimento da democracia, como instrumento de pressão necessário para combater a concentração de renda, essa que teria avançado no período autoritário recém-superado. Furtado reconhecia, adicionalmente, a centralidade de uma política para a educação, pois "o ativo de mais peso na distribuição da renda é aquele que está incorporado como capacitação no próprio fator humano" (Furtado, 1992, p. 56).

Finalmente, as duas últimas proposições eram: ampliar o investimento em pesquisa científica e tecnológica, tentando superar o dualismo da estrutura de consumo da sociedade, das classes de alta renda com consumo de sofisticada tecnologia, e da massa da população com consumo de bens produzidos com tecnologia obsoleta. E, por outro lado, Furtado defendia a reconstrução de amplos projetos nacionais de futuro, esposados por diferentes segmentos da sociedade. Tais projetos deveriam ser resultantes tanto da pesquisa e da criação intelectual, que captassem a essência dos desafios da realidade social, como também do confronto com as iniciativas emergentes da sociedade civil.

O alvorecer do século XXI, não obstante, introduzia novos impasses para a concretização de um projeto de superação do subdesenvolvimento. Furtado nessa altura se questiona sobre a viabilidade de disseminação do próprio modelo de sociedade consumista difundido ao longo da Era de Ouro do capitalismo. Para o economista, a civilização constituída a partir da Re- 
volução Industrial apontava de "forma inexorável para grandes calamidades" (Furtado, 1992, p. 76).

O modelo de sociedade arquitetado durante o século XX teria exigido uma elevada concentração de riqueza, submetendo uma parcela da população mundial à penúria, fome e pobreza, enquanto outra parcela vinha desperdiçando e comprometendo os recursos do planeta. Era evidente o esgotamento da camada de ozônio, o aquecimento do planeta, a destruição da biodiversidade, a poluição dos rios, oceanos e a exportação de resíduos tóxicos. Furtado escreve no ano da ECO-92, realizada no Rio de Janeiro, evento que o autor classifica como "a plataforma em que pela primeira vez se defende a tese de que existe uma fatura ecológica a ser paga pelos países que [...] se beneficiaram da formidável destruição de recursos não-renováveis" (Furtado, 1992, p. 77).

Com isso, Furtado antecipava a crítica sobre o modelo da sociedade neoliberal em quase vinte anos, pois ficava evidente que inclusive os "países que estão na vanguarda do progresso tecnológico também parecem haver tomado uma direção errada" (Furtado, 2002,p. 78). O dilema entre crescimento e limites ecológicos como enfrentado por Furtado pode ser observado na síntese que mais recentemente foi ilustrada por Kate Raworth em sua Economia Donut, de 2019. Como Furtado vai reiteradamente defender ao longo dos anos 1990, o futuro deveria ser conduzido a partir de duas ideias: garantir a satisfação das necessidades fundamentais, como presentes na Declaração Universal dos Direitos Humanos, e defender a responsabilidade internacional para preservação do patrimônio natural (Furtado, 1992, p. 78).

Por outro lado, sua análise sobre a incapacidade do atual modelo econômico atender aos interesses de toda a população, como presente em seu conceito de heterogeneidade estrutural, parece ter entrado na agenda política apenas a partir da crise de 2008 , e de poderosas narrativas como as de Thomas Piketty em O capital do século XXI, de 2013. A mensagem era clara: a economia regulada pelo mercado não garantiria a disseminação dos benefícios do progresso tecnológico para toda a sociedade; o fosso entre ricos e pobres se ampliava tanto quanto as polarizações políticas extremistas; a fragilização dos instrumentos de intervenção na economia teria tornado os Estados nacionais quase estéreis no sentido de equalizar as desigualdades.

Se a solução para a superação do subdesenvolvimento ainda se centrava num discurso de projeto nacional, isto é, da organização do sistema econômico nacional, ao apresentar "A nova concepção de desenvolvimento", Furtado 
sugere que os projetos de futuro não poderiam ser mais nacionalmente isolados. Se no pós-guerra foi a ameaça de destruição nuclear que abalou a civilização, no fim do século o risco tornou-se a "hecatombe" ecológica, na qual as soluções para a sobrevivência dos povos deveriam ocorrer a partir da cooperação, ou "pelo menos a conscientização progressiva da maioria deles" (Furtado, 1992, p. 78).

No alvorecer do novo milênio, o método histórico-estrutural de Celso Furtado foi mobilizado pelo autor para produzir sua nova síntese sobre o Brasil e o mundo em meio à difusão do neoliberalismo. Sua arguta leitura sobre a conjuntura produzia em fins do século XX uma nova interpretação sobre os dilemas do desenvolvimento econômico, em que camadas do estruturalismo latino-americano foram sobrepostas, confrontando antigas teses com os novos condicionamentos econômicos e políticos mundiais, em parte reiterando velhos diagnósticos, mas também atualizando os caminhos para a promoção de seus projetos sociais. Passados alguns anos de uma batalha quixotesca, a não realização das promessas propaladas pelos defensores da economia globalizada abririam novo espaço para recuperação das ideias do cavaleiro inexistente.

\section{Celso Furtado e o visconde partido ao meio}

Passadas duas décadas "perdidas", marcadas pelo baixo crescimento econômico e pela substituição da agenda desenvolvimentista por um conjunto de reformas econômicas neoliberais, a partir dos anos 2000, com o novo contexto de crescimento econômico internacional e com a ascensão de governos de esquerda na América Latina, a semântica desenvolvimentista voltou ao debate nacional. Celso Furtado, nesse contexto, como intelectual que inspirava parcela significativa da nova elite dirigente e era o patrono do nacional-desenvolvimentismo, voltou ao centro do debate econômico. ${ }^{16}$

Fosse pelo real tamanho do desafio de reconstruir um projeto de desenvolvimento nos quadros da hegemonia neoliberal, fosse pelos custos políticos de produzir as necessárias reformas estruturais para superar a condição permanente do subdesenvolvimento, é possível dizer que as ideias de Celso Furtado foram praticadas pela metade. Isto é, assim como a personagem $\mathrm{Me}-$

\footnotetext{
${ }^{16}$ Como ilustração, vale conferir o seminário de criação do Centro Internacional Celso Furtado de Políticas para o Desenvolvimento, realizado em novembro de 2005, em Brasília, tendo como participantes membros do governo Lula, como Aloizio Mercadante, Guido Mantega e Marco Aurélio Garcia. As contribuições do seminário foram publicadas em Cadernos do Desenvolvimento (v. 1, n. 1, 2006).
} 
dardo di Terralba, o Visconde partido ao meio de Italo Calvino, as ideias de Furtado, ao serem implementadas como política econômica, foram fissuradas nas duas últimas décadas. Mesmo tendo lutado contra a especialização do olhar do economista, sugerindo que as análises econômicas se encontrassem com os processos históricos, sociais e culturais, a apropriação de suas ideias na proposição das políticas econômicas nacionais não rompeu com os limites estruturais para promover as necessárias transformações da sociedade. ${ }^{17}$

O conceito de novo desenvolvimentismo ganhou maior visibilidade a partir do Governo Lula, em especial no seu segundo mandato, dado o bom desempenho da maioria dos indicadores macroeconômicos e a ampliação do escopo das políticas sociais. Esse período de relativa estabilidade da macroeconomia brasileira - tanto pela elevação dos preços das matérias-primas, como pelas condições excepcionais de financiamento externo, denominado por José Antonio Ocampo de "bonança macroeconômica"-, produzia um ciclo inequívoco de crescimento econômico (Ocampo, 2007, p. 79). ${ }^{18}$

No cenário político nacional, depois de anos de baixo crescimento, a perda de influência do pensamento neoliberal, adicionada à ascensão do planejamento estatal, foram os vetores de solidificação do pensamento novo desenvolvimentista. Como ilustra a avaliação de Bresser em 2006: "Diante do fracasso das políticas neoliberais recomendadas pelos países ricos para promover a estabilidade macroeconômica e o desenvolvimento, existe, hoje, na América Latina, um claro movimento de rejeição da ortodoxia convencional" (Bresser-Pereira, 2006a, p. 5).

Sem produzir uma exaustiva recuperação das políticas dos governos do PT, não há menor dúvida de que existem paralelos evidentes entre ações estabelecidas durante os mandatos de Lula e Dilma e os diagnósticos e sugestões produzidos por Celso Furtado ao longo de sua trajetória. Não que as

\footnotetext{
${ }^{17} \mathrm{Na}$ última década realizou-se um grande esforço de análise sobre o projeto político dos governos do PT. No calor do mandato, emergiu o debate sobre o caráter do novo desenvolvimentismo; mais recentemente, tem-se produzido uma avaliação das realizações e dos limites das políticas empreendidas sobre o período petista. Sem sermos exaustivos, elencamos alguns estudos que nos ajudaram a produzir essas páginas. $\mathrm{O}$ texto que abre a polêmica do novo desenvolvimentismo é o de Bresser (2006). Para o debate em torno do conceito, sugerimos: Sicsú et al. (2007), Bastos (2012), Carneiro (2012) e Milane e Sales (2018). Para uma avaliação mais recente sobre o legado e limites da política petista, conferir: Biancarelli (2014), Loureiro e Saad-Filho (2019), Rossi, Mello e Bastos (2020) e Bielschowsky (2020).

${ }^{18} \mathrm{O}$ clima de estabilidade não afetou apenas a economia brasileira, mas foi amplamente favorável às economias latino-americanas. O seu auge foi resultado da expansão da demanda chinesa por commodities e foi alavancada pela especulação financeira produzida a partir da política monetária dos Estados Unidos, resultando em baixa taxa de juros e créditos abundantes (Soares, 2014).
} 
políticas estivessem necessariamente espelhadas pelas teses do economista, mas certamente a nova elite dirigente vinha de uma formação inspirada no nacional-desenvolvimentismo e na influente interpretação furtadiana. ${ }^{19}$ Não obstante, vale lembrar que Furtado faleceu em novembro de 2004, tendo acompanhado apenas uma pequena parte dos governos do PT, inclusive sem deixar de fazer significativas críticas às políticas macroeconômicas de caráter neoliberal. Possivelmente a influência mais direta de Furtado no governo de Lula tenha sido, quanto muito, a indicação de Carlos Lessa para a presidência do BNDES (Alencar, 2004).

Como ponto de partida da possível aproximação da ação política com a interpretação furtadiana, devemos destacar a imediata priorização do combate à pobreza e à desigualdade no discurso do governo federal - como com os programas Fome Zero e do Bolsa Família. Em torno de 2007, como passaria a propalar o então ministro da Fazenda, Guido Mantega, o governo vinha empreendendo uma política "social desenvolvimentista", com ênfase na distribuição de renda. Para tanto, a dinamização do mercado interno e a atuação racional do Estado eram os meios decisivos para produzir as políticas sociais do governo federal. ${ }^{20}$ Mercado interno que, para Celso Furtado, ainda em 2004, era uma aposta para o desenvolvimento no caso brasileiro, por ser um raro caso de país com grande potencial de crescimento por meio da integração de parcela da população ainda alijada do mercado:" a saída para o Brasil consiste em dinamizar o mercado interno" (Furtado, 2004b, p. 3).

Possivelmente a principal síntese do projeto político do governo foi produzida por Alóisio Mercadante Oliva em sua tese de doutorado, defendida no simbólico ano de 2010, último ano de mandato de Lula, quando o presidente desfrutava de aprovação recorde. Para Mercadante, o modelo de desenvolvimento econômico conduzido nos dois governos Lula teria produzido uma política de desenvolvimento social. O motor da economia passou

\footnotetext{
${ }^{19}$ Guido Mantega, então presidente do BNDES, durante a abertura do evento de criação do Centro Internacional Celso Furtado, afirmava a inequívoca influência do economista: "Ele [Furtado] não teve tempo de perceber as mudanças importantes que vêm ocorrendo no país a partir do governo Lula, que tem procurado por em prática uma parte da doutrina do Celso Furtado, evidentemente nos termos atuais da economia brasileira e internacional, e buscando promover um tipo de crescimento que combine o crescimento econômico com a inclusão social." (Mantega, 2006, p. 31).

${ }^{20}$ No que diz respeito à preocupação com a dinamização do mercado interno no governo de Lula, vale lembrar o relevante papel do Ministério da Integração Regional, a recriação da Sudene, assim como a criação de políticas para a pequena propriedade rural, por meio do Ministério do Desenvolvimento Agrário. Por outro lado, a ideia do Estado como órgão técnico e racional foi muito valorizada, com significativa expansão dos concursos e de instituições públicas.
} 
a ser o mercado de consumo de massas, sustentado por uma política de fortalecimento da democracia, de uma inserção externa soberana e de uma nova política energética, decorrente da descoberta do pré-sal (Oliva, 2010).

A política social se firmou no período tanto nos mecanismos de transferência de renda quanto também numa política de elevação de salário mínimo. Como Ricardo Bielschowsky chama atenção, os documentos da campanha do Partido dos Trabalhadores (1994 e 2002), como os planos plurianuais dos governos Lula (2003 e 2007), estariam alicerçados na crença de que o aumento da renda das classes mais pobres gerava uma expansão na demanda por bens e serviços modernos. Assim, o PT abraçava a tese de Antonio Barros de Castro de 1990, na qual se defendia que a estrutura produtiva brasileira estaria preparada para acolher um modelo de crescimento com redistribuição de renda pelo mercado interno de consumo de massa (Bielschowsky, 2020).

O resultado de tais políticas foi de um efetivo crescimento da economia, com significativa queda do desemprego e de elevação real do salário mínimo - com impactos efetivos no mercado de trabalho e nas aposentadorias -, abrindo toda uma discussão sobre o caráter da chamada "nova classe média" brasileira. As oportunidades abertas com o crescimento econômico e a melhoria da renda da base da população ampliavam as demandas sociais e de melhoria da qualidade de vida. Alguns programas, tais como de expansão das vagas em universidades - públicas e privadas -, respondiam em parte a essas demandas, mas eram ainda restritas no sentido de produzir uma real transformação da estrutura social do país.

A coalizão política dos governos do PT, ao atender tanto as demandas sociais da base da pirâmide, como também aquelas dos grandes grupos econômicos e financeiros do país, se permitiu certa autonomia do governo para promoção de políticas sociais, por outro lado o guiou por meio de uma política econômica conservadora. Dando continuidade às bases macroeconômicas da política psdbista, isto é, o tripé de metas fiscais, de inflação e de câmbio flutuante, o governo Lula era saudado pelo "mercado". O cenário internacional permitiu que o país vivesse um relativo ambiente de autonomia, podendo construir políticas com reconhecimento internacional, ${ }^{21}$ mas efetivamente

\footnotetext{
${ }^{21}$ Sobre as relações do país na economia internacional, o Brasil desfrutou de certa autonomia e, inclusive, significativo prestígio internacional. A constituição dos BRICs, como a articulação entre países emergentes e com relevante investimento do governo brasileiro a partir de 2003, ilustrava a tentativa de romper com a hierarquia financeira internacional. Com limitada capacidade de se reverter às forças do mercado e das grandes empresas estrangeiras, os centros nacionais de decisão de países subdesenvolvidos precisavam reduzir a dependência dos países. Como defendia Celso Furtado, desde o final dos anos 1970, países como o
} 
sem garantir um real controle dos centros internos de decisão, preocupação recorrente de Furtado.

O resultado foi a promoção de uma política econômica que produziu a apreciação cambial, no contexto de boom das commodities, e controle da inflação. Como aponta Bastos, essa política cumpria paradoxalmente com a expansão do mercado de massas de bens de consumo e serviços urbanos, com barateamento das importações, mas reiterava problemas estruturais, com a perda de encadeamento da estrutura produtiva nacional, o que limitaria o próprio potencial de expansão do mercado interno ao longo do tempo (Bastos, 2012, p. 799-800).

O argumento se aproxima das críticas de Bresser Pereira sobre o modelo econômico do governo petista, partindo do diagnóstico sobre a "doença holandesa" brasileira dos anos 2000, em sua tese sobre o novo desenvolvimentismo. Para o autor, o elevado custo de uma política de câmbio valorizado foi o de produzir um processo de desindustrialização, reduzindo a competitividade dos produtos nacionais às importações (Bresser-Pereira, 2006a).

Em suma, não bastava elevar o salário mínimo ou criar empregos, mas era preciso produzir empregos de qualidade, estimular a estrutura produtiva nacional. Como sintetizava Furtado pouco antes de seu falecimento, com um olhar crítico para a política econômica até então conduzida pelo governo: "Duas frentes seriam, em meu entender, capazes de suscitar uma autêntica mudança qualitativa no desenvolvimento do país: a reforma agrária e uma industrialização que facilite o acesso às tecnologias de vanguarda". Em suma, para construir esse caminho, defendia: "A nós, cientistas sociais, caberá a responsabilidade maior de velar para que não se repitam os erros do passado. Ou melhor, para que não voltem a ser adotadas falsas políticas de desenvolvimento cujos benefícios se concentram nas mãos de poucos." (Furtado, 2004, p. 4).

Evidentemente, os governos do PT pautaram uma agenda em que a distribuição de renda era um objetivo prioritário. Com a elevação da renda das classes baixas e os dados do índice de Gini, a impressão era a de que efetivamente vivíamos uma redução da desigualdade social. Contudo, tanto a ampliação da insatisfação social ilustrada pelas jornadas de junho de 2013 quanto a disponibilização dos dados tributários a partir de 2014 incentivaram

Brasil deviam criar mecanismos de se contrapor ao poder financeiro das transnacionais por meio de uma articulação de economias que esposavam os mesmos interesses. Por exemplo, Furtado defendia a ideia de uma Opep dos países endividados ante a dívida externa latino-americana (Furtado, 1978, p. 116, 1982, p. 59). 
novas análises no sentido de apontar esses limites da política econômica e social promovidos no último decênio. Se os dados tributários trariam a realidade de que a redução da desigualdade, conforme imaginado, não teria sido tão efetiva - houve redução da disparidade salarial, mas não da concentração de renda e da riqueza da sociedade -, as manifestações de junho materializavam os impasses do governo. Afinal, a coalizão de forças construída pelo lulismo colocava-se agora em bases muito mais frágeis (Loureiro; Saad-Filho, 2019). ${ }^{22}$

A crise econômica, que em 2008 foi provisoriamente espantada por meio de uma política anticíclica que impulsionou o mercado interno, em 2013 se aprofundou e o governo não tinha mais a possibilidade de reproduzir aquela política econômica de outrora. O esgotamento do potencial de ampliação do mercado interno de massas, especialmente com a manutenção de um câmbio apreciado e do elevado grau de importações, vinha sendo apontado antes mesmo de a crise estourar (Bastos, 2012, p. 796-797; Bielschowsky, 2012, p. 730).

A impossibilidade de manter o modelo de crescimento sustentado nos primeiros anos dos governos do PT exigiu que Dilma Rousseff rompesse com a coalizão política original. A sobrevivência do governo e a tentativa de dar continuidade às conquistas sociais exigiam uma pauta de reformas mais profundas. Como Furtado vivenciara nos anos 1960, também nos anos 2010 o impasse econômico decretou um posicionamento político: lá foram as reformas de base defendidas por Furtado desde 1962; aqui, com o governo Dilma a partir de 2011, a agenda foi a de abandonar o tripé macroeconômico e de defender a "nova matriz econômica". ${ }^{23}$ Nas duas ocasiões, a aposta na coalizão política em torno de um projeto nacional permaneceu enquanto os ciclos expansivos permitiram: as tentativas de aprofundamento das reformas culminaram com rupturas políticas que deixariam cicatrizes duradouras na sociedade.

\section{Ainda há formação? Ou a Brazilification do mundo...}

Em provocativo ensaio publicado em 2012, Marcos Nobre propõe que o paradigma da "formação", diante as transformações do capitalismo ocor-

\footnotetext{
${ }^{22}$ Fernando Rugistky (2016) usa a expressão de um “antimilagre”, em que os empregos criados no período teriam se concentrado em setores de baixa produtividade.

${ }^{23}$ Possivelmente a nova matriz econômica seria mais próxima das velhas ideias furtadianas, de um nacional-desenvolvimento, mas sem o devido uso do método histórico estrutural para compreender o novo contexto econômico do período. Para uma sistematização das medidas da nova matriz, ver Singer (2015).
} 
ridas a partir dos anos 1980, teria se esgotado. Formação: o gênero ensaístico e interpretativo que ensinou os brasileiros a conhecerem sua própria história e cultura, assim como apresentou os permanentes limites da incompletude formadora da nação (Arantes, 1997, p. 11-12).

Formação, para Nobre, era a síntese interpretativa de uma vertente vitoriosa de se pensar o Brasil, constituída em meados do século XX, por meio dos pares modernização-democracia e modernidade-justiça social. Formação econômica do Brasil, como diz Francisco de Oliveira (2003b, p. 19), colocou Furtado no panteão dos demiurgos do Brasil, com decisivo poder ideológico, pois em meio ao processo de industrialização, o autor explicava e construía o país de seus dias. Assim, o modelo nacional-desenvolvimentista representado por Furtado era, por sua vez, a síntese de um projeto político hegemonizado intelectualmente na proposição de um Brasil moderno (Nobre, 2012, p. 17).

O paradigma dominante durante as transformações da sociedade do pós-guerra encontraria o ano de 1964 como uma dura cisão. A industrialização avançava, mas a democracia e a justiça social teriam sido abortadas. Por dentro do regime militar, a concepção por trás do gênero de formação sobrevivia, sofrendo dura crítica de seus herdeiros que buscavam responder mais uma vez às causas da incompletude da formação, mas mantendo o paradigma como dominante dentro dos meios universitários.

Marcos Nobre defende que a crise definitiva do paradigma emerge nos anos 1980. Para o autor "dois movimentos tectônicos" tornaram caduco o paradigma de formação, como o projeto de país segundo os dizeres do nacional-desenvolvimentismo. No contexto internacional, a globalização liquidou com as forças nacionais como instrumentos de reversão do quadro de atraso - ainda que o contexto tenha autorizado inédita autonomia decisória interna -, enquanto a redemocratização teria aberto a sociedade para uma estrutura mais complexa. Na conclusão do autor, a "formação" se encerrou, mesmo que não tenha se completado como na promessa existente no paradigma.

Fernando Henrique Cardoso reitera o coro sobre a necessidade de encontrar novos prismas para pensar o Brasil: "A questão nacional não poderá ser pensada apenas do ângulo econômico e estatal, nem de modo isolado, como se o país fosse, em si, uma unidade autônoma para a reflexão". Segue o autor reivindicando que as "novas percepções ideológico-culturais" devem assimilar novas vozes sociais, com novas "formas de participação cidadã", ao 
mesmo tempo em que a "lupa" que nos posiciona na sociedade mundial seja confrontada com "telescópios que nos situem no universo mais amplo" (Cardoso, 2013, p. 14).

Entre Formação econômica do Brasil e Brasil: a construção interrompida são mais de trinta anos de produção intelectual de Celso Furtado. Mesmo que Furtado tenha sustentado suas bases teóricas e históricas ao longo de sua trajetória intelectual, não é possível dizer que o autor tenha apenas reproduzido suas conclusões de meados do século XX para indicar caminhos nos anos 1990.

Celso Furtado reconhece que o desafio de concretizar um projeto nacional como pensado nos anos 1950 tinha se tornado ainda mais dificil. Num ambiente de globalização, de incertezas no cenário internacional e da ofensiva liberal, os novos atores políticos jogavam praticamente uma pá de cal na ideia de um projeto nacional.

O diagnóstico era coerente com suas proposições de décadas anteriores. Celso Furtado vinha desde suas obras dos anos 1970 dando muito destaque para o papel das empresas transacionais nas economias subdesenvolvidas. Sua utopia recomendava contrapor o poder das empresas transnacionais - que interferiam nos centros internos de decisão -, uma coordenação de Estados nacionais que pudessem definir salários e reduzir a dependência financeira e tecnológica. ${ }^{24}$ Ainda assim, todavia, o projeto nacional seria a forma de conduzir o Estado, de garantir as prioridades por meio da racionalidade substantiva e de encontrar o caminho das utopias de concretização da formação nacional.

Mas é possível dizer que nas últimas décadas não somente o espaço de atuação do Estado nacional foi reduzido, como também os próprios modelos de futuro têm sido extintos. No auge da teoria do desenvolvimento e das políticas de industrialização da periferia, o Estado de bem-estar Europeu era um modelo para se inspirar. Afinal, se formação é o instrumento para compreender a especificidade e o caráter único que explica a não concretização da nação brasileira, formação é também a busca de um espelho, um fim positivo. Nesse sentido, não ter se formado, para aquele paradigma e para aquela geração, era não ter alcançado o grau de desenvolvimento e homogeneização

\footnotetext{
${ }^{24}$ A proposta de Furtado está evidenciada em Criatividade e dependência (1978), e em obras de início dos anos 1980, como $A$ nova dependência (1982), a ideia aparece novamente, mas como uma Opep dos países endividados, também para garantir o contraponto ao poder dos credores.
} 
social das sociedades europeias ou do modelo de consumo e de democracia dos Estados Unidos.

Mas o que fazer quando o capitalismo contemporâneo tem produzido não somente o afunilamento das portas para a construção de uma nação, mas a própria destruição dos modelos de nação que outrora se almejou reproduzir?

Como mencionamos antes, não foi preciso os estudos de Piketty sobre desigualdade ou de Kate Raworth sobre os limites ambientais para Furtado captar os impasses do século XXI. Para o autor, já em 1992 eram visíveis as tendências de ampliação do desemprego e da massa de destituídos, de queda da qualidade e do alcance dos serviços públicos, de expansão da poluição endêmica, e de diminuição da autonomia dos Estados nas tomadas de decisão (Furtado, 1992, p. 26).

Enfim, não são mais as economias subdesenvolvidas que precisam trilhar mudanças para alcançar os padrões de sociabilidade "modernos", mas os próprios países desenvolvidos tendem a passar por um processo de "Brazilification". 25

Em suma, produzir a homogeneização social dependia, antes de tudo, de restaurar o sentido do Estado Nacional, tanto na periferia quanto nas próprias economias centrais. A obra de Celso Furtado é uma ode contra a hegemonia liberal e a racionalidade instrumental do capitalismo, como na imagem de Karl Polanyi, um combate ao moinho satânico que tritura os indivíduos como mercadorias dispensáveis na nova ordem do neoliberalismo (Tavares, 2006, p. 45).

Assim, acertam Nobre e Cardoso ao indicarem que os projetos de futuro precisam ser repensados para o século XXI. Celso Furtado, sendo fiel ao método histórico-estrutural, não deixa de reconhecer essa necessidade: sugere a cooperação internacional por meio de órgãos como as Nações Unidas para enfrentar temas como a desigualdade e os limites ecológicos; tanto quanto defende a atuação do Estado na promoção da educação, da habilitação e de uma política científica e tecnológica.

O paradigma da formação, portanto, tampouco parece estar esgotado, como reiterava Furtado em 2003: "Um país como o Brasil tem sempre problemas novos, pois está em formação” (Furtado, 2003, p. 23). O Estado nacional

\footnotetext{
${ }^{25}$ O termo foi cunhado por Douglas Coupland em Generation X: tales for an accelerated culture (1991), caracterizando o processo de desaparecimento das classes médias. Essa leitura está bem marcante no recente livro de Lance Taylor (2020), e no Brasil, tinha sido também significativamente indicado por Francisco de Oliveira (2003a).
} 
ainda é o instrumento que pode se contrapor às forças do mercado, discernir entre a objetividade instrumental e a substantiva. Sem ter superado as adversidades causadoras da incompletude formativa e com heranças de nosso passado ainda perturbando a sociedade contemporânea, interpretações como as de Furtado são instrumentos ainda relevantes para pensar em projetos de futuro. Por isso, Bernardo Ricupero se vale da ideia de uma paradoxal necessidade de se voltar ao uso do paradigma de "formação", afinal a "nossa má-formação" se generaliza e ganha caráter mundial (Ricupero, 2008, p. 68).

As ideias e o método histórico de Furtado, portanto, ainda demonstram vigor para a compreensão da realidade tanto quanto para a proposição de projetos de futuro. O projeto reformista de Celso Furtado, não obstante, tem sido confrontado com uma conjuntura econômica e social cada dia mais restrita para transformações sociais: em 2020, a crise sanitária explicitou e agudizou a dimensão da crise econômica, política e social da sociedade contemporânea. Sem o projeto iluminista de progresso universal que nos foi roubado, são urgentes novos horizontes de expectativa. Como o método histórico e as ideias de Furtado nos ensinam, novos contextos exigem novas utopias, novos modelos de sociedade que precisam ser pactuados.

\section{Referências}

ALENCAR, K. Celso Furtado, Lula e Carlos Lessa. Folha de São Paulo online. 21 de novembro de 2004.

ARANTES, P. Providências de um crítico literário na periferia do capitalismo. In: ARANTES, Otília; ARANTES, Paulo. Sentido da formação. São Paulo: Paz e terra, p. 7-65, 1997.

BASTOS, P. P. Z. A economia política do novo-desenvolvimentismo e do social desenvolvimentismo. Economia e Sociedade. Campinas, v. 21, num. esp., p. 779-810, 2012.

BERNANKE, B. The great moderation. In: KOENIG, Evan F. Taylor rule and the transformation of monetary policy. Hoover Institute Press, p. 145-162, 2004.

BIANCARELLI, A. A Era Lula e sua questão econômica principal: crescimento, mercado interno e distribuição de renda. Revista do Instituto de Estudos Brasileiros. n. 54, p. 263-288, 2014. 
BIANCONI, R. Estagnação latino-americana e estratégia brasileira de desenvolvimento: análises do início do exílio de Celso Furtado. Revista História econômica e história de empresas. v. 19 (1), p. 155-188, 2016.

BIELSCHOWSKY, R. Cinquenta anos de pensamento da CEPAL. Rio de Janeiro: Record, 2000.

BIELSCHOWSKY, R. Estratégia de desenvolvimento e as três frentes de expansão no Brasil: um desenho conceitual. Economia e Sociedade. Campinas, v. 21, num. esp., p. 729-747, 2012.

BIELSCHOWSKY, R. O pensamento estruturalista de Celso Furtado e sua atualidade no centenário de seu nascimento. Revisa Rosa. n. 1, v. 2, on-line, 2020.

BRESSER-PEREIRA, L. C. O novo desenvolvimentismo e a economia convencional. São Paulo em Perspectiva. v. 20, n. 3, p. 5-24, jul./set. 2006a.

BRESSER-PEIREIRA, L. C. Restrições externas e o financiamento. Cadernos do desenvolvimento. Rio de Janeiro, ano 1 (1), p. 77-94, 2006b.

BRESSER-PEREIRA, L. C. Método e paixão em Celso Furtado. In:BRESSER-PEREIRA, Luiz Carlos; REGO, José Márcio (Org.). A grande esperança em Celso Furtado. São Paulo: Editora 34, p. 19-43, 2001.

CARDOSO, F. H. Empresário industrial e desenvolvimento econômico no Brasil. Rio de Janeiro: Difel, 1972.

CARDOSO, F. H. Pensadores que inventaram o Brasil. São Paulo: Companhia das Letras, 2013.

CARDOSO, F. H.; FALETTO, E. (1967). Dependência e desenvolvimento na América Latina. São Paulo: Difel, 1970.

CARNEIRO, R. M.Velhos e novos desenvolvimentismos. Economia e Sociedade. Campinas, v. 21, num. esp., p. 749-778, 2012.

CASTRO, A. B. O Brasil a caminho do mercado de consumo de massa. In: 
REISVELLOSO, João Paulo (Org.). As perspectivas do Brasil e o Novo Governo. São Paulo: Nobel, 1990.

COUTINHO, M. Furtado e seus críticos: da estagnação à retomada do crescimento econômico. Economia e Sociedade. v. 28, n. 3, p. 741-759, 2019.

FONSECA, P. C. D. Celso Furtado e o estruturalismo como método. In: SAES, Alexandre; BARBOSA, Alexandre. Celso Furtado e os 60 anos de Formação econômica do Brasil. São Paulo: Sesc/BBM, p. 225-235, 2021.

FUKUYAMA, F. The end of History? The National Interest. n. 16, p. 3-18, 1989.

FUKUYAMA, F. The end of History and the last man. The Free Press, 1992.

FURTADO, C. M. A pré-revolução brasileira. Rio de Janeiro: Fundo de Cultura, 1962.

FURTADO, C. M. A dialética do desenvolvimento. Rio de Janeiro: Fundo de Cultura, 1964.

FURTADO, C. M. Subdesenvolvimento e estagnação na América Latina. Rio de Janeiro: Civilização Brasileira, 1966.

FURTADO, C. M. (1967). Teoria e política do desenvolvimento econômico. São Paulo: Editora Nacional, 1977.

FURTADO, C. M. Análise do "modelo" brasileiro. Rio de Janeiro: Civilização Brasileira, 1972.

FURTADO, C. M. O mito do desenvolvimento econômico. Rio de Janeiro: Paz e Terra, 1974.

FURTADO, C. M. Criatividade e dependência na civilização industrial. Rio de Janeiro: Paz e Terra, 1978.

FURTADO, C. M. A nova dependência, dívida externa e monetarismo. Rio de Janeiro, Paz e Terra, 1982. 
FURTADO, C. M. Brasil: a construção interrompida. Rio de Janeiro: Paz e Terra, 1992.

FURTADO, C. M. O capitalismo global. Rio de Janeiro: Paz e terra, 1998.

FURTADO, C. M. Em busca de novo modelo. Rio de Janeiro: Paz e terra, 2002.

FURTADO, C. M. O Brasil no século XXI: entrevista com Celso Furtado. Estatísticas do século XXI. Rio de Janeiro: IBGE, 2003.

FURTADO, C. M. Os desafios da nova geração. Jornal dos economistas, p. 3-4, jun. 2004a.

FURTADO, C. M. Receitas para o crescimento. [Entrevista concedida a] Álvaro Kassab. Jornal da Unicamp, 27 de setembro a 3 de outubro, 2004b.

FURTADO, C. M. Obra autobiográfica. São Paulo: Companhia das Letras, 2014.

HOBSBAWM, E. A era dos extremos. São Paulo: Companhia das Letras, 1994.

LOUREIRO, P. M.; SAAD-FILHO, A. The limits of pragmatism: the rise and fall of the brazilian workers' party (2002-2016). Latin American Perspectives. issue 224, v. 46, n. 1, p. 66-84, 2019.

LOVE, J. Furtado e o estruturalismo. BRESSER-PEREIRA, Luiz Carlos; REGO, José Márcio (Org.). A grande esperança em Celso Furtado. São Paulo: Editora 34, p. 221-252, 2001.

MALLORQUIN, C. Celso Furtado, um retrato intelectual. Rio de Janeiro: Contraponto-Xamã, 2005.

MANTEGA, G. Sessão de abertura. Cadernos do desenvolvimento. Rio de Janeiro: Centro Internacional Celso Furtado, ano 1 (1), p. 29-32, 2006.

MANZATTO, R.; SAES, A. Celso Furtado, intérprete da dependência. Revista do Instituto de Estudos Brasileiro. v. 78 (1), 2021.

MILANI, A. M.; SALES, R. Do “desenvolvimentismo” ao "novo desenvol- 
vimentismo" no Brasil: a evolução do conceito. Revista de Sociedade Brasileira de Economia Política. n. 51, p. 47-67, set./dez. 2018.

NOBRE, M. Da "formação" às "redes": filosofia e cultura depois da modernização. Cadernos de Filosofia Alemã. n. 19, p. 13-36, 2012.

OLIVA, A. M. As bases do novo desenvolvimentismo: análise do governo Lula. Campinas, 2010. Tese (Doutorado em Economia - Universidade Estadual de Campinas).

OLIVEIRA, F. A economia brasileira: crítica à razão dualista. Estudos Cebrap. n. 2, p. 4-82, 1972.

OLIVEIRA, F. Crítica à razão dualista: o ornitorrinco. São Paulo: Boitempo, 2003a.

OLIVEIRA, F. A navegação venturosa: ensaios sobre Celso Furtado. São Paulo: Boitempo, 2003b.

OCAMPO,J.A.A macroeconomia da bonança econômica latino-americana. Revista Cepal. Número especial em português, 2007.

PINTO, A. (1970). Natureza e implicações da "heterogeneidade estrutural" da América Latina. In: BIELSCHOWSKY, Ricardo (Org.). Cinquenta anos de pensamento na CEPAL. Rio de Janeiro: Record, p. 567-588, 2000.

RICUPERO, B. Da formação à forma: ainda as "ideias fora de lugar". Lua nova. n. 73, p. 59-69, 2008.

RODRIGUEZ, O. O estruturalismo latino-americano. Rio de Janeiro: Civilização Brasileira, 2009.

ROSSI, P.; MELLO, G.; BASTOS, P. P.The growth model of the PT governments: a furtadian view of the limits of recent brazilian development. Latin American Perspectives. v. 47, n. 1, p.100-114, 2020.

RUGITSKY, F. Milagre, miragem, antimilagre: a economia política dos governos Lula e as raízes da crise atual. Revista Fevereiro. v. 9, p. 40-50, 2016. 
SAES, A.; MANZATTO, R.; SOUSA, E. S. de. Ensino e pesquisa em história econômica: perfil docente e das disciplinas de história econômica nos cursos de graduação de economia no Brasil. História econômica \& História de Empresas. v. 18, n. 2, p. 229-264, jul./dez. 2015.

SAES, A.; MANZATTO, R. Os sessenta anos de Formação econômica do Brasil: pensamento, história e historiografia. In: SAES, Alexandre; BARBOSA, Alexandre. Celso Furtado e os 60 anos de Formação econômica do Brasil. São Paulo: Sesc/BBM, p. 83-118, 2021.

SAES, F.; SAES, A. História econômica geral. São Paulo: Saraiva, 2013.

SINGER, A. Cutucando onças com varas curtas: o ensaio desenvolvimentista no primeiro mandato de Dilma Rousseff (2011-2014). Novos estudos CEBRAP. v. 102, p. 39-67, 2015.

SISCÚ, J.; et al. Por que novo-desenvolvimentismo? Revista economia política. v. 27, n. 4 (108), p. 507-524, out./dez. 2007.

SOARES, J. A. R. Uma interpretação do novo desenvolvimentismo a partir da conjuntura econômica da América Latina. Cepal - Coleção documentos de projetos. Nações Unidas, Santiago, Chile. LC/W. 589, mar. 2014.

SOUSA, R. N. O realismo inverossímil na literatura combinatória de Ítalo Calvino. Araraquara, 2007. Dissertação (Mestrado - Universidade Estadual Paulista).

STIGLITZ, J. E. The roaring nineties: a new history of the world's most prosperous decade. New York:W.W. Norton \& Company, 2003.

TAVARES, M. da C.; SERRA, J. (1971). Além da estagnação: uma discussão sobre o estilo de desenvolvimento recente. In: BIELSCHOWSKY, Ricardo (Org.). Cinquenta anos de pensamento na Cepal. Rio de Janeiro: Record, p. $589-608,2000$.

TAVARES, M. da C. Conferência introdutória. Cadernos do desenvolvimento. Rio de Janeiro: Centro Internacional Celso Furtado, ano 1 (1), p.37-49, 2006.

TAYLOR, L. Macroeconomic inequality from Reagan to Trump: market power, 
wage repression, asset price inflation, and industrial decline. Cambridge: United Kingdom, 2020.

WILLIAMSON, J. What Washington Means by Policy Reform. WILLIAMSON, John (Org.). Latin American readjustment: how much has happened. Washington: Peterson Institute for International Economics, 1989. 